\title{
Comparison of Hollow Sprint and Interval Training in Increasing Speed of 100 M Sprint Test
}

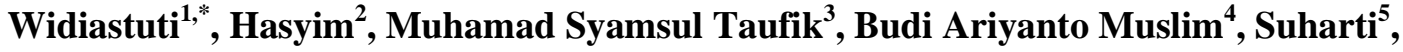 \\ Soleh Solahuddin ${ }^{6}$, Silvy Juditya ${ }^{7}$, Karisdha ${ }^{8}$ \\ ${ }^{1}$ Universitas Negeri Jakarta, Indonesia \\ ${ }^{2}$ Universitas Negeri Makassar, Indonesia \\ ${ }^{3}$ Faculty of Teacher and Education, University of Suryakancana, Indonesia \\ ${ }^{4}$ Ministry of Youth and Sports of the Republic of Indonesia, Indonesia \\ ${ }^{5}$ Universitas PGRI Adibuana Surabaya, Indonesia \\ ${ }^{6}$ Faculty of Teacher and Education, University of Sriwijaya, Indonesia \\ ${ }^{7}$ Faculty of Teacher Training and Education, STKIP Pasundan, Indonesia \\ ${ }^{8}$ Universitas Negeri Jakarta, Indonesia
}

Received October 29, 2021; Revised January 5, 2022; Accepted January 17, 2022

\section{Cite This Paper in the following Citation Styles}

(a): [1] Widiastuti, Hasyim, Muhamad Syamsul Taufik, Budi Ariyanto Muslim, Suharti, Soleh Solahuddin, Silvy Yuditya, karisdha , "Comparison of Hollow Sprint and Interval Training in Increasing Speed of 100 M Sprint Test," International Journal of Human Movement and Sports Sciences, Vol. 10, No. 1, pp. 79 - 84, 2022. DOI: 10.13189/saj.2022.100111.

(b): Widiastuti, Hasyim, Muhamad Syamsul Taufik, Budi Ariyanto Muslim, Suharti, Soleh Solahuddin, Silvy Yuditya, karisdha (2022). Comparison of Hollow Sprint and Interval Training in Increasing Speed of 100 M Sprint Test. International Journal of Human Movement and Sports Sciences, 10(1), 79 - 84. DOI: 10.13189/saj.2022.100111.

Copyright $₫ 2022$ by authors, all rights reserved. Authors agree that this article remains permanently open access under the terms of the Creative Commons Attribution License 4.0 International License

\begin{abstract}
Hollow Sprint Training (accelerated sprint) starts with a slow running motion. Interval training consists of repetitions of a maximum intensity exercise. Detailed data on these two exercises for which one is more effective in increasing the $100 \mathrm{~m}$ run is very limited. This study aims to determine the difference in the effect of hollow sprints and interval training in increasing the running speed of 100 meters. Method: A total of 20 samples of 100-meter sprint event athletes participated in this study. The method used was an experiment with a Comparative Design model. The data collection technique used in this study was a test instrument. They were divided into two groups which designed as hollow sprint group (A) and interval training group (B). This study used comparative experimental method where athletes in each group were given two different treatments and a 100meter speed test before and after the treatment. Results: 1 ) The p-value of the hollow sprint group or group A (0.004) is smaller than 0.05 , which can be concluded that group A had a significant increase. 2) The p-value of the interval group or group B $(0.006)$ is smaller than 0.05 , which can be concluded that group B had a significant increase. 3) There is a significant difference between hollow sprint and interval training on
\end{abstract}

increasing 100 -meter running speed, the p-value $(0.035)$ is smaller than 0.05. Conclusions: Interval training is more effective than hollow sprint training in increasing athletes' 100 meters running speed.

Keywords Hollow Sprint, Interval Training, Speed, Sprint

\section{Introduction}

Track and field or athletics is a sport that contains competitions of running, jumping, and throwing [1]. Track and field is the oldest sport, which is called the parent of all sports, because track and field include the fundamental movements of all other sports, such as; walking, running, jumping, and throwing which are generally also used in this sport, are further developed to attract more attention so that there are more enthusiasts [2]. Track and field is a sport that has the potential to produce athletes who can participate in Tokyo Olympics 2020 [3].This research focuses more on sprint, which is an event in track and field. 
Sprint can be define as running at full speed along the distance that must be traveled or up to a predetermined distance, and the runner is called a sprinter [4]. Sprint events include 100 meters, 200 meters and 400 meters sprints [5]. The difference between sprint, medium distance, and long-distance running lies in the running speed of the runners. The ability to quickly accelerate from a static position and maintain high running velocities are clear determinants of performance in sprint race events [6], [7]. These activities can be done well in a health-enhancing manner such as physical exercise, if relevant muscle groups are involved, the intensity is sufficient, and the recovery is appropriate. We can observe that in a sprint race, athletes attempt to run to the finish line as fast as possible using their maximum speed [8]. This is by the definition of sprint (short-distance running) as many of running from start to finish are carried out at maximum speed. Furthermore, according to Bompa and Buzzichelli [9], short distance running takes 10-15 seconds and is an anaerobic sport, because the higher the speed, the greater the anaerobic energy source.

The basic requirement in a series of sprinting movements, by goal of sprint, is speed. Sport performances are characterized by high-speed actions, while the sportsmen should take quick decisions and solve the sport-specific tasks occurring during the match [10]. Šimonek et al., stated that what is needed for all sprints and hurdles is speed, by the understanding that sprint means running a distance with prompt explosion [11]. According to Douglas et al. [12], sprinters need well-developed physical performances to be able to compete in track and field sprint events. Speed is one of the physical performances that is really needed to perform successive movements in the shortest amount of time in the sprint events. In addition, the paradigm of speed in sport is sprinting, therefore, it is important to know the parameters that determine it [13]. As qualified sprint athlete must meet the requirements for some qualities, such as speed, strength, endurance, and relatively strong flexibility, so coaches and athletes must pay attention to methods while training physical performances in sprint, in which the speed is the main determining factor of an athlete's performance [14]. Furthermore, Zhou et al. stated that how to improve sprint athletes' speed is also a concern for every trainer. In the context of athletes' speed development, according, it must be carried out intensively and well planned for a very long period, special attention must be able to be properly directed and on target in order to develop the performances of athletes who are really prepared for the championship that will be followed to perform at their best and acquire maximum achievement and These factors need to be improved through training, essential to support performance when in the field [8].

This study aims to determine the effect differences of hollow sprint and interval training in increasing 100 meters running speed. As in any sprint race, the primary objective of the $100 \mathrm{~m}$ sprint is to cover the designated distance in the shortest time possible [15]. The Hollow Sprint (acceleration sprint) training starts from a slow running motion and increases its speed over time. It is effective for developing the stride (straddle length) in sprinting, and increasing reaction speed, especially simple reactions. Interval training consists of repetitions of maximal intensity exercise, usually performed in a short period of exercises and interspersed with rest periods on each exercise from $30 \mathrm{~s}$ to $4 \mathrm{~min}$ [16], [17]. Interval training is associated with performance enhancement [18] such as developing muscle strength and reaction speed. The interval is intended as recovery time that is sufficient for athletes to be able to put maximum effort in the next repetition. Physical exercise and sports performance involve effective and targeted body movements [19], Which of these two training items can be a better treatment to increase the 100-meter running speed and at the same time be an update of the current training, it seems that the author is interested in this research In the context of the previous problems related to the advantages and disadvantages of 100-meter running training, this study aims to determine the difference in the effect of hollow sprints and interval training in increasing 100-meter running speed To the authors' knowledge, no research has looked at the effect of differences in perforated sprints and interval training on an increase in running speed of 100 -meter. We hypothesize that there is a difference in the effect of hollow sprints and interval training on increasing the 100-meter running speed.

\section{Material and Method}

The research method used was an experiment with a Comparative Design model. The data collection technique used in this study was a test instrument. The sampling technique used purposive sampling technique. They were divided into two groups which were designed as hollow sprint group (A) and interval training group (B). This study used comparative experimental method where athletes in each group will be given two different treatments and a 100-meter speed test before and after the treatment.

Comparisons were made between the test results of the treatments to find out which treatment is more effective in improving athletes' speed. The pretest-posttest group design can be seen in Table 1 .

Table 1. The Pretest-Posttest Comparative Group Design

\begin{tabular}{ccc}
\hline Pre-test & Treatment & Post-test \\
\hline $\mathrm{A}_{1}$ & $\mathrm{HOL}$ & $\mathrm{A}_{2}$ \\
$\mathrm{~B}_{1}$ & $\mathrm{INT}$ & $\mathrm{B}_{2}$ \\
\hline
\end{tabular}

Note: A1: Pre-test group A, A2 : Post-test group A, B1: Pre-test group B, B2: Post-test group B, HOL: Hollow sprint, INT: Interval training 
Table 2. Data Description Analysis of 100 Meters Running Speed Pre-test and Post Test Results

\begin{tabular}{cccccccccc}
\hline Variabel & N & $\begin{array}{c}\text { Pre-Test } \\
\text { Min }\end{array}$ & $\begin{array}{c}\text { Post } \\
\text { Test } \\
\text { Mini }\end{array}$ & $\begin{array}{c}\text { Pre-Test } \\
\text { Max }\end{array}$ & $\begin{array}{c}\text { Post } \\
\text { Test } \\
\text { Max }\end{array}$ & $\begin{array}{c}\text { Pre- Test } \\
\text { Mean }\end{array}$ & $\begin{array}{c}\text { Post } \\
\text { Test } \\
\text { Mean }\end{array}$ & $\begin{array}{c}\text { Pre-test } \\
\text { St } \\
\text { Deviation }\end{array}$ & $\begin{array}{c}\text { Post Test } \\
\text { St } \\
\text { Deviation }\end{array}$ \\
\hline Hollow Sprint & 10 & 13.15 & 11.92 & 13.85 & 12.75 & 13.35 & 12.34 & 0.29 & 0.34 \\
Interval & 10 & 13.09 & 11.93 & 14.27 & 13.30 & 13.55 & 12.55 & 0.044 & 0.53 \\
\hline
\end{tabular}

\section{Participants}

A total of 20 athletes from the Indonesian Athletic Association (PASI) of Cianjur District were asked to take part in this research. All athletes were short-distance runners who actively participated in the 100-meter sprint race. The samples were chosen using purposive sampling technique with the criteria of the best 100 -meter sprint race athletes in the Cianjur district which were divided into two groups, namely: the Hollow Sprint Training Group in a structured and deliberate manner into a training program by 10 athletes (group A); and Interval Training Group which was performed by 10 athletes (group B).

\section{Performance indicators}

Data reliability

To ensure the reliability of the data, five randomly selected matches were coded by the authors of this study and then compared with those provided by Instant Scout. The Kappa (K) values obtained ranged from .92 to .98. The procedure and statistical analysis in this study were using SPSS 25.

\section{Results}

Data description analysis of 100 meters running speed pre-test and post Test results of athletes who were being given hollow sprint and interval training treatments can be seen in Table 2.

The results of data processing in Table 2 show that the average speed of hollow sprint group is 13.35 with a standard deviation of 0.29 . The lowest score is 13.15 and the highest score is 13.85. Meanwhile, the interval training group speed average is 13.55 with a standard deviation of 0.044. The lowest score was 13.09 and the highest score was 14.27. Data description analysis of 100 meters running speed post-test results of athletes who were being given hollow sprint and interval training treatments can the average speed of hollow sprint group is 12.34 with a standard deviation of 0.29 . The lowest score is 11.92 and the highest score is 12.7. Meanwhile, the interval training group speed average is 12.55 with standard deviation of 0.53 . The lowest score was 11.93 and the highest score was 13.30 .

A hypothesis test of the Hollow Sprint improvement results was obtained from a 1-sample $t$ analysis using Minitab 16 software. The research hypothesis is:
Table 3. Group A (Hollow Sprint) Hypothesis

\begin{tabular}{ccc}
\hline Data & Average Value & p-value \\
\hline Group A Value & 0.05 & 0.004 \\
\hline
\end{tabular}

The result above shows that the significance value is 0.004 or the p-value is less than the significance value of 0.05 , which means that $\mathrm{H} 1$ is accepted.

It can be concluded that there is a significant increase of PASI Cianjur athletes' 100-meter running speed who were given Hollow Sprint training. Hypothesis test of the Interval Training improvement results were obtained from a 1-sample $\mathrm{t}$ analysis using Minitab 16 software. The research hypothesis is:

Table 4. Group B (Interval Training) Hypothesis

\begin{tabular}{ccc}
\hline Data & Nilai Rerata & p-value \\
\hline Group B Value & 0.05 & 0.006 \\
\hline
\end{tabular}

The result above shows that the significance value is 0.006 or the p-value is less than the significance value of 0.05 , so $\mathrm{H} 1$ is accepted.

It can be concluded that there is a significant increase in PASI Cianjur athletes 100 meter running speed who were given Interval Training. From the results of Hollow Sprint and Interval Forms effect on PASI (Cianjur athletes 100 meters running speed, hypotheses were tested statistically to compare the significant differences between treatment groups. The results of the tests can be seen in the following Table 5.

Table 5. Comparison Hypothesis

\begin{tabular}{cccc}
\hline Treatments & Mean & $\begin{array}{c}\text { Mean } \\
\text { Differences }\end{array}$ & p-value \\
\hline $\begin{array}{c}\text { Hollow sprint } \\
\text { value }\end{array}$ & 1,14 & & \\
$\begin{array}{c}\text { Interval training } \\
\text { value }\end{array}$ & 0,94 & 0,2 & 0.035 \\
\hline
\end{tabular}

The results above show that there is a significant difference in the results of the value of the hollow sprint and the interval training as proven by a significance value of 0.035 which is smaller than the significance level $(0.035<0.05)$. This is also proven by the mean difference of 0.2 which indicates an increase in athletes' 100-meters running speed using the hollow sprint training group with an average of 1.14 , higher than the interval of 0.94 . In this case, the 100 meters running speed was not taken from the average maximum time, but from the minimum or smallest average time (inversely proportional). Therefore, the less 
time it takes, the better speed of the 100 -meter running is considered. So, it can be concluded that the interval training is better than the hollow sprint training for improving athletes' speed.

\section{Discussion}

The main objective of this study was to determine the difference between hollow sprints and the effect of interval training on increasing running speed of 100 meters. While hollow sprint training is proven to increase running speed and implies that a constant pace slightly below the threshold leads to maximal performance [20]. Interval training also shows a significant effect on athletes' performance, including speed. The assessment of the various aspects related to the practice of training [21], Therefore to improve athlete's performance it is necessary to use the right training method Recently [22], it has become clear that in order to achieve high results during matches in several sports; it is necessary to simultaneously develop some physical capacity during the training period.

This study specifically shows that hollow sprint training is effective to improve the speed of short-distance running. There was a significant improvement on athletes' 100-meters running speed after being given the hollow sprint training. This finding was in line with those of previous studies. Furthermore, using the ETM or IHT did not inhibit increases in VO2max. Other previous studies [23] respectively suggest that eight weeks and six weeks of hollow sprint training can significantly improve the speed, while [24] argue that hollow sprints can be used as an alternative in training speed for sprinters. Therefore hollow sprint training seems to be a promising method to be applied in collective sports, as it can be adapted to specific needs of athletes' training.

Interval training has also shown significant effects on short-distance running performance in this study. Athletes' speed was significantly improved after the interval training treatment. This finding supports other investigations which have reported athletes' improvement in speed [25]-[27]. Buccheit et al., and Koral et al., argue that six sessions of sprint interval training improves running performance in trained athletes while Fajrin et al., show that six week interval training with three sessions of exercises a week improve speed significantly. In this study, hollow sprint and interval training could statistically increase speed, which supports previous findings. Although both trainings have some effects on improving speed, the results of this study show significant differences between hollow sprint training and interval training groups after implementing the training program. The results of this study show that interval training was more effective in increasing athletes' $100-$ meters running speed than hollow sprint training. The average speed of the hollow sprint training group in post-test were higher than the interval training group, which indicates that the hollow sprint training group took more time in finishing 100-meters than the interval training group. One factor that might caused this significant difference was the variation between individuals in response to a given loading condition [28], [29]. Therefore, trainers or coaches may need to observe the type of exercises that are suitable for applying to each individual so that the training can provide maximum results. However, although this study did not observe the character of the participating samples more comprehensively, they are expected to be able to represent short-distance athletes broadly so that the differences that emerged indicate which exercises are more effective to be applied in general.

\section{Conclusions}

Based on the results of the data analysis, the authors can conclude the following: There is a significant increase of athletes' 100 meters running speed who were being given hollow sprint training. There is a significant increase of athletes' 100 meters running speed who were being given interval training. There is a significant difference between hollow sprint and interval training in increasing athletes' 100 meters running speed. Based on the results, it can be concluded that the interval training is more effective in increasing athletes' 100 meters running speed. Therefore, the authors suggest the following: It is necessary to apply or to use interval training in increasing athletes' 100 meters running speed. The results of this study can be used by trainers as guidance in planning a training program to improve speed. Further studies can use these training forms to analyze their effect on athletes' speed endurance.

\section{Supporting Agencies}

We are grateful for the support of the Indonesian Athletic Associations, Cianjur regency. We are also grateful for the support from the campus department and the extended family of the Jakarta State University Physical Education Doctoral Program.

\section{Disclosure Statement}

No potential conflict of interest was reported by the authors.

\section{REFERENCES}

[1] M. Kazoglu and Z. O. Yuruk, "Comparison of the physical fitness levels in nursing home residents and community-dwelling older adults,” Arch. Gerontol. Geriatr., vol. 89, no. May, p. 104106, 2020, doi: 10.1016/j.archger.2020.104106. 
[2] J. R. Grove et al., "Training distress and performance readiness: Laboratory and field validation of a brief self-report measure,” Scand. J. Med. Sci. Sport., 2014, doi: $10.1111 /$ sms.12214.

[3] N. Adigüzel, "Education of star excursion balance performance among young male athletes," African Educ. Res. J., vol. 8, no. 2, pp. 147-151, 2020, doi: 10.30918/aerj.82.20.032.

[4] N. Naser, A. Ali, and P. Macadam, "Physical and physiological demands of futsal,” J. Exerc. Sci. Fit., vol. 15, no. 2, pp. 76-80, 2017, doi: 10.1016/j.jesf.2017.09.001.

[5] D. Barbieri, L. Zaccagni, V. Babić, M. Rakovac, M. Mišigoj-Duraković, and E. Gualdi-Russo, "Body composition and size in sprint athletes," J. Sports Med. Phys. Fitness, vol. 57, no. 9, pp. 1142-1146, Sep. 2017, doi: 10.23736/S0022-4707.17.06925-0.

[6] N. E. Bezodis, S. Willwacher, and A. I. T. Salo, "The Biomechanics of the Track and Field Sprint Start: A Narrative Review," Sports Medicine, vol. 49, no. 9. Springer International Publishing, pp. 1345-1364, Sep. 2019, doi: 10.1007/s40279-019-01138-1.

[7] D. M. Mirkov, O. M. Knezevic, A. Garcia-Ramos, M. Čoh, and N. Šarabon, "Gender-related differences in mechanics of the sprint start and sprint acceleration of top national-level sprinters,” Int. J. Environ. Res. Public Health, vol. 17, no. 18, pp. 1-11, Sep. 2020, doi: 10.3390/ijerph17186447.

[8] Muslimin, M. S. Taufik, and E. F. Amalia, "Development of defensive training futsal model university of suryakancana,” Int. J. Hum. Mov. Sport. Sci., vol. 9, no. 2, pp. 236-241, 2021, doi: 10.13189/saj.2021.090211.

[9] T. O. Bompa and C. A. Buzzichelli, Peridization: Theory and Methodology of Training, vol. 53, no. 9. 2019.

[10] T. O. Bompa and C. Buzzichelli, Periodization-6th Edition: Theory and Methodology of Training. 2018.

[11] J. Šimonek, P. Horička, and J. Hianik, "The differences in acceleration, maximal speed and agility between soccer, basketball, volleyball and handball players,” J. Hum. Sport Exerc., vol. 12, no. 1, pp. 73-82, 2017, doi: 10.14198/jhse.2017.121.06.

[12] J. Douglas, S. Pearson, A. Ross, and M. McGuigan, "Kinetic determinants of reactive strength in highly trained sprint athletes,” J. Strength Cond. Res., vol. 32, no. 6, pp. 1562-1570, 2018, doi: 10.1519/jsc.0000000000002245.

[13] G. Carmona Dalmases and C. González-Haro, “Análisis de la capacidad de aceleración en mujeres atletas de modalidades de velocidad," Apunt. Educ. Física y Deport., no. 107, pp. 69-77, Mar. 2012, doi: 10.5672/apunts.2014-0983.es.(2012/1).107.07.

[14] X. Zhou, L. Tang, D. Lin, and W. Han, "Virtual \& augmented reality for biological microscope in experiment education,” Virtual Real. Intell. Hardw., vol. 2, no. 4, pp. 316-329, 2020, doi: 10.1016/j.vrih.2020.07.004.

[15] L. J. G. Mitchell, B. Rattray, J. Fowlie, P. U. Saunders, and B. David, "The impact of different training load quantification and modelling methodologies on performance predictions in elite swimmers," Eur. J. Sport Sci., vol. 0, no. 0, pp. 1-29, 2020, doi:

\subsection{0/17461391.2020.1719211}

[16] G. Tschakert and P. Hofmann, "High-intensity intermittent exercise: Methodological and physiological aspects," International Journal of Sports Physiology and Performance, vol. 8, no. 6. Human Kinetics Publishers Inc., pp. 600-610, 2013, doi: 10.1123/ijspp.8.6.600.

[17] R. Hebisz, P. Hebisz, J. Borkowski, and M. Zatoń, "Differences in physiological responses to interval training in cyclists with and without interval training experience," $J$. Hum. Kinet., vol. 50, no. 1, pp. 93-101, Apr. 2016, doi: 10.1515/hukin-2015-0147.

[18] M. J. Gibala, "Physiological basis of interval training for performance enhancement," Exp. Physiol., 2020, doi: 10.1113/EP088190.

[19] M. S. Taufik, Widiastuti, Y. Setiakarnawijaya, and F. Dlis, "Effect of circuit and interval training on vo2max in futsal players,” J. Phys. Educ. Sport, vol. 21, no. 4, pp. 2283-2288, 2021, doi: 10.7752/jpes.2021.s4305.

[20] B. A. Gasser, "Analysis of speed strategies during World Orienteering Championships,” J. Hum. Sport Exerc., vol. 13, no. 2, pp. 254-266, 2018, doi:10.14198/jhse.2018.132. 01.

[21] Á. M. Montero, "Sports training in ancient Greece and its supposed modernity,” J. Hum. Sport Exerc., vol. 15, no. 1, pp. 163-176, 2020, doi: 10.14198/jhse.2020.151.15.

[22] V. L. G. Panissa, U. F. Julio, C. M. P. E. Silva, L. V. Andreato, F. Hardt, and E. Franchini, "Effects of interval time between high-intensity intermittent aerobic exercise on strength performance: Analysis in individuals with different training background," J. Hum. Sport Exerc., vol. 7, no. 4, pp. 815-825, 2012, doi: 10.4100/jhse.2012.74.09.

[23] B. N. Bellovary et al., "Effects of high-intensity interval training while using a breathing-restrictive mask compared to intermittent hypobaric hypoxia," J. Hum. Sport Exerc., vol. 14, no. 4, pp. 821-833, 2019, doi: 10.14198/jhse.2019.144.11.

[24] D. Alonso-Fernández, F. Lima-Correa, F. Gutierrez-Sánchez, and O. A. G. De Vicuña, "Effects of a high-intensity interval training protocol based on functional exercises on performance and body composition in handball female players,” J. Hum. Sport Exerc., vol. 12, no. 4, pp. 1186-1198, 2017, doi: 10.14198/jhse.2017.124.05.

[25] M. Buchheit, A. Mendez-Villanueva, M. Quod, T. Quesnel, and S. Ahmaidi, "Improving acceleration and repeated sprint ability in well-trained adolescent handball players: Speed versus sprint interval training,” Int. J. Sports Physiol. Perform., vol. 5, no. 2, pp. 152-164, Jun. 2010, doi: 10.1123/ijspp.5.2.152.

[26] J. Koral, D. J. Oranchuk, R. Herrera, and G. Y. Millet, "Six sessions of sprint interval training improves running performance in trained athletes," J. Strength Cond. Res., vol. 32, no. 3, pp. 617-623, Mar. 2018, doi: 10.1519/jsc.0000000000002286.

[27] F. Fajrin, N. W. Kusnanik, and Wijono, "Effects of High Intensity Interval Training on Increasing Explosive Power, Speed, and Agility,” J. Phys. Conf. Ser., vol. 947, no. 1, 2018, doi: 10.1088/1742-6596/947/1/012045.

[28] R. Whiteley, C. Hansen, A. Thomson, V. Sideris, and M. G. 
Wilson, "Lower limb EMG activation during reduced gravity running on an incline. Speed matters more than hills irrespective of indicated bodyweight," Gait Posture, vol. 83, pp. 52-59, Jan. 2021, doi: 10.1016/j.gaitpost.2020.09.029.
[29] L. R. Williams, T. W. Standifird, A. Creer, H. B. Fong, and D. W. Powell, "Ground reaction force profiles during inclined running at iso-efficiency speeds,” J. Biomech., vol. 113, p. 110107, Dec. 2020, doi: 10.1016/j.jbiomech.2020.1 10107. 